\title{
Prepubertal PTU treatment in rat increases Sertoli cell number and sperm production
}

\author{
André F A Figueiredoํ, Natália Teixeira Wnuk ${ }^{1}$, Amanda O Tavares ${ }^{1}$, José Rafael Miranda², \\ Rex $\mathrm{A} \mathrm{Hess}^{3}$, Luiz Renato de França ${ }^{1}$ and Guilherme M J Costa ${ }^{1}$ \\ ${ }^{1}$ Department of Morphology, Institute of Biological Sciences, Laboratory of Cellular Biology, Federal University of \\ Minas Gerais - UFMG, Belo Horizonte, Minas Gerais, Brazil, ${ }^{2}$ Department of Veterinary Medicine, Federal \\ University of Lavras, Lavras, Minas Gerais - UFLA, Brazil and ${ }^{3}$ Department of Comparative Biosciences, University of \\ Illinois, Urbana Champaign, Illinois, USA \\ Correspondence should be addressed to L R França or G M J Costa; Email: Irfranca@icb.ufmg.br or gmjc@ufmg.br
}

\begin{abstract}
The number of Sertoli cells (SCs) ultimately determines the upper limit of sperm production in the testis. Previous studies have shown that thyroid hormones (TH) receptors are abundantly expressed in developing SCs; therefore, it was highly significant to discover that transient neonatal hypothyroidism induced by the goitrogen 6-n-propyl-2-thiouracil (PTU) can extend SCs proliferation beyond the first 2 weeks postnatal and increase testis weight and sperm production. Further studies concluded that treatment must begin before day 8 post birth in rats. Recent studies, however, showed that SCs present in the transition region at the rete testis exhibit a more immature phenotype and have prolonged mitotic activity, which led to the hypothesis that SCs in this region will retain the capacity to respond to PTU treatment over a longer period of time. In the present study, male Wistar rats were treated with PTU from days 21 to $\mathbf{4 0}$ and were evaluated at $\mathbf{4 0}$ and $\mathbf{1 6 0}$ days of age. Similar to neonatal rat SCs, it was demonstrated that prepubertal SCs in the transition region have a high mitotic activity and are highly sensitive to TH levels. This delayed, transient hypothyroidism resulted in significantly increased testis weight, SCs number and daily sperm production. The results demonstrate for the first time that Sertoli cells showing plasticity in the transition region can be stimulated to increase proliferation and contribute to a late stage surge in testis weight and sperm output.

Reproduction (2019) 158 199-209
\end{abstract}

\section{Introduction}

Sertoli cells (SCs) play a crucial role in testis physiology, from the fetal period of organ differentiation to the adult (Magre \& Jost 1991), controlling general growth and development of the seminiferous tubules and providing support required for survival and evolution of germ cells into sperm (França et al. 1995, 2016, Rotgers et al. 2018). The importance of this key somatic testicular cell is best exemplified by the fact that the magnitude of sperm production in sexually mature animals is ultimately determined by the total number of Sertoli cells per testis (Orth et al. 1988, Sharpe 1994, Hess \& França 2007, França et al. 2016).

Although it is well established that SCs become terminally differentiated before puberty, recent studies have shown that a subset of rodent SCs are still capable of proliferation in the transition region after this period, having mitotic activity even in adults (Figueiredo et al. 2016, Kulibin \& Malolina 2016, Malolina \& Kulibin 2017). This particular region, which is a border between two embryologically distinct areas (Roosen-
Runge 1961, Svingen \& Koopman 2013), is where seminiferous tubules (STs) connect to the rete testis, representing a unique functional environment that exhibits substantial plasticity. Therefore, the transition region may serve as an area capable of forming a new spermatogonial stem cell niche (Aiyama et al. 2015), given that new SCs are continually available for an extended period of time (Figueiredo et al. 2016). Therefore, we hypothesized that the transition region represents an area where the ST could grow in length after puberty.

Endocrine factors regulate reproductive physiology (Wagner et al. 2008), including the capacity of SCs to proliferate (Cooke et al. 2005, Holsberger \& Cooke 2005). Several hormones, such as the follicle-stimulating hormone $(\mathrm{FSH})$, activin $\mathrm{A}$, androgens and estrogens, among others, are involved in SCs proliferation (Orth 1984, Meachem et al. 2005, Nicholls et al. 2013, Lucas et al. 2014). Thyroid hormones (THs) are a key factor in stimulating their differentiation (Cooke et al. 1994, França et al. 1995, Auharek \& França 2010, Sun et al. 2015). The drug 6-n-propyl-2-thiouracil (PTU) is used to 
treat hyperthyroidism and thus an antithyroid medication that decreases TH by blocking the conversion of thyroxin (T4) to triiodothyronine (T3) (Taurog et al. 1976, Shiroozu et al. 1983, Crofton \& Zoeller 2005, Dong 2006). Interestingly, PTU has been used experimentally in animals to modulate SC proliferation and differentiation, by creating a transient hypothyroidism (Cooke et al. 1992, França et al. 1995, Auharek \& França 2010, Waqas et al. 2019). In 1991, Cooke and colleagues demonstrated that PTU treatment in rats, from birth to weaning, increased testis size by $80 \%$ and sperm production by nearly $140 \%$. This surge in sperm output was explained by an increase of $157 \%$ in the number of Sertoli cells (Hess et al. 1993), which was eventually shown to be due to a delay in differentiation, allowing the cells to continue dividing beyond the normal period after birth (Cooke et al. 1994, França et al. 1995). Further studies showed that TH inhibits SCs proliferation, while transient hypothyroidism does the opposite (Van Haaster et al. 1992); however, the increase in testis weight and SC proliferation depends on the timing of a return to the euthyroid condition (Rijntjes et al. 2017).

After testing several different treatment periods, it was concluded that if treatment began on postnatal day 8 or later PTU would not increase testis weight (Cooke et al. 1992). However, our research group, having demonstrated that SCs in the transition region (TRSCs) have a prolonged mitotic activity (Figueiredo et al. 2016), hypothesized that this unique region may retain SCs capable of responding to PTU over a longer period of time. Therefore, the present study investigated the effects of PTU treatment on TRSCs proliferation, by creating a transient hypothyroidism during an alternate window of prepubertal development, but after the accepted age when SC have ceased to divide (2140 days old). The results demonstrate for the first time that Sertoli cells in the transition region at the rete testis can be stimulated by late stage transient hypothyroidism to increase proliferation, which contributes to a significant increase in testis weight and sperm output at 160 days of age. Because hypothyroidism remains an ongoing concern during pregnancy (Gutvirtz et al. 2019), these data provide new awareness regarding testis growth, niche formation and spermatogenesis progression in experimental animals and young boys.

\section{Materials and methods}

\author{
Animals \\ In this study, 37 male Wistar rats (Rattus novergicus) were \\ used. All experiments were performed in strict accordance \\ with the Guidelines for Animal Use and Experimentation as \\ set by the Animal Experimentation Ethics Committees from the \\ Federal University of Minas Gerais (Belo Horizonte, Brazil; \\ CEUA 398/2013).
}

\section{Experimental design}

Four experimental groups, with eight male rats each, were evaluated. The animals were killed at different ages (40 and 160 days old) and distributed into control and PTU-treated groups. Each group was kept in separate cages and the PTU treatment (6-propil-2-tiouracil, Sigma) was given from 21 to 40 days of age. Day 21 was chosen to begin treatment, because it is well established that rat SCs ceased dividing at this age (Orth 1982, Almirón \& Chemes 1988). PTU was added to the drinking water at $0.03 \%(\mathrm{w} / \mathrm{v})$ and, to improve PTU-palatability, ten drops of sweetener (Stevia Linea) were added per liter of solution. Five young male rats were used as starting controls for histological evaluation of the testes and thyroid glands, as well as for the initial measurements of free thyroxine (T4) (see below). All groups were kept in an average temperature of $22^{\circ} \mathrm{C}$ and $70 \%$ average humidity with 12-h photoperiod. Water and pelleted food were available ad libitum. The experimental design is shown in Fig. 1. For all groups, body weights (BW) were measured weekly from day 21 to day 160.

\section{Testis weight and gonadosomatic index}

All rats were killed by pentobarbital overdose (100 mg/kg BW). Testis weight (TW) was obtained after the testis was separated from the epididymis. The net TW was estimated by subtracting weights of the tunica albuginea and the mediastinum (Johnson et al. 1981). Because testicular density is very close to 1 (França 1991), testicular volume was considered equal to its weight. The gonadosomatic index (testes mass divided by body weight) was estimated for all investigated animals.

\section{Histomorphometric analysis}

For histological and morphometric analyses, testis and thyroid gland fragments were collected, weighed and fixed by immersion for $24 \mathrm{~h}$ in $4 \%$ glutaraldehyde in a $0.05 \mathrm{M}$ phosphate buffer, $\mathrm{pH} 7.2$ at $4{ }^{\circ} \mathrm{C}$. The specimens were dehydrated in ethanol and routinely embedded in glycol-methacrylate (Historesin, Leica). Histological sections, $4 \mu \mathrm{m}$ thick, were obtained and then stained with toluidine blue solution in $1 \%$ sodium borate.

\section{Volume densities of the testis parenchyma components}

The volume densities (\%) of the ST were obtained using a graticule containing 441 intersections. All histomorphometric analyses used the Image J v.1.45s software (Image Processing and Analysis, in Java). The intersections that coincided with tunica propria, seminiferous epithelium and tubular lumen were counted in 15 randomly chosen fields by horizontal scanning of the histological sections. Five images per histological section and spaced $200 \mu \mathrm{m}$ apart were evaluated at $400 \times$ magnification.

\section{Seminiferous tubules and thyroid follicular lumen diameters}

The mean diameter of the ST was obtained from cross-sections of tubules that were round or nearly round, regardless of 


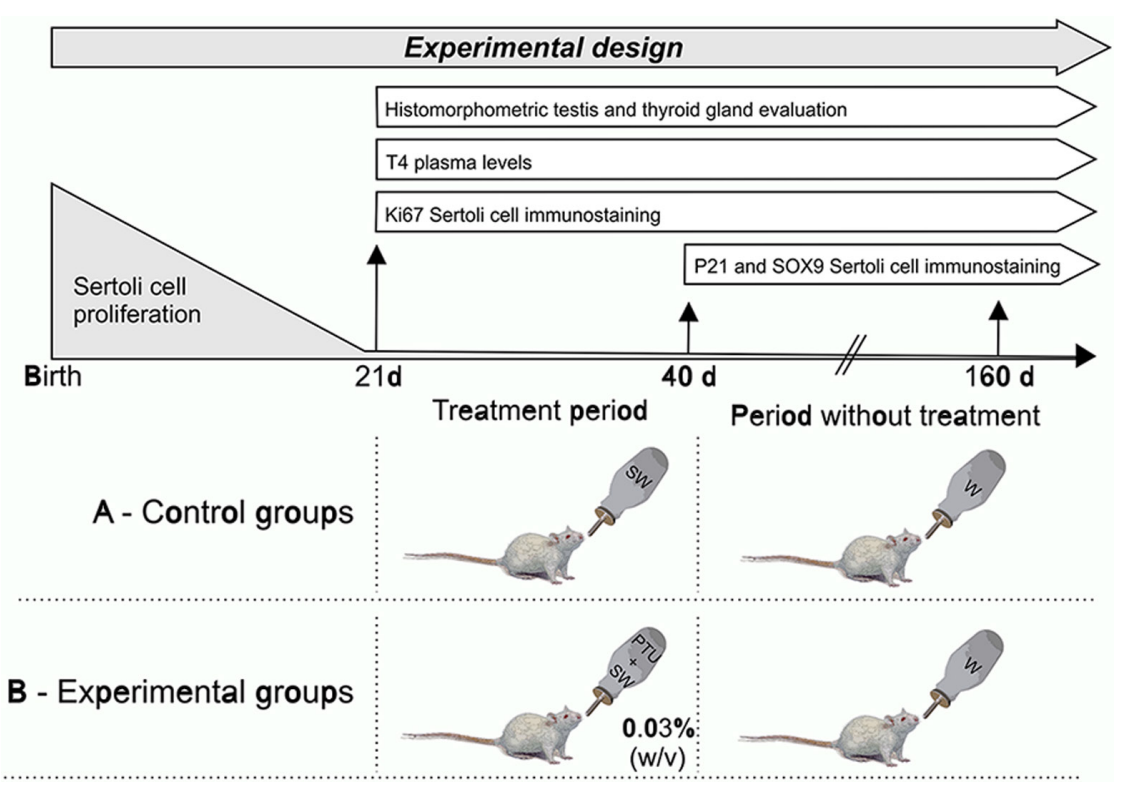

Figure 1 Schematic illustration of the experimental design. Five 21-day-old male rats were used for the immunostaining evaluation of the Sertoli cells proliferation (SCs), the testis and thyroid gland histological status, as well as for thyroid hormone (T4) plasma level. Because SCs are not expected to proliferate after 3 weeks of age (Orth 1982, Almirón \& Chemes 1988), except in the transition region (Figueiredo et al. 2016), PTU treatment began on day 21 post-partum and extended until day 40. The animals were killed on 40 and 160 days post birth. At these two latter ages, 32 male rats were evaluated (eight per each experimental group). PTU, 6-propil-2thiouracil; S, sweetener; W, water. the stage of the seminiferous epithelium cycle (SEC). Thirty ST cross-sections were measured at $100 \times$ of magnification per animal. Regarding thyroid follicular lumen, their mean diameters were estimated according to the following formula: (major diameter + minor diameter)/2 (Rajab et al. 2017). Thirty thyroid follicles, randomly chosen, were measured at $200 \times$ of magnification per animal.

\section{Seminiferous tubules and transition region lengths}

The length of the ST, expressed in meters, was estimated according to the method of Attal and Courot (1963), considering the values for the total volume of the ST and the mean tubular diameter obtained for each animal. Thus, the total length of the ST was determined by dividing ST volume by the squared radius of the tubule (tubular diameter divided per two) times the pi value (Johnson \& Neaves 1981). The individual length of the transition region, expressed in micrometers, was obtained from regions presenting a clear and continuous connection between the ST and the rete testis.

\section{Evaluation of the most advanced germ cell type}

In order to verify if the PTU treatment affects the germ cell progression and differentiation, particularly in 40-dayold rats, the most advanced germ cell type was evaluated. This evaluation was performed also based on the germ cell associations and, when deemed pertinent, the development of the acrosomal system and the morphology of the developing spermatid nucleus were considered.

\section{Cell counting}

In order to estimate some key testis parameters, SCs nucleoli and round spermatids nuclei were counted in ten round or nearly round ST cross-sections, chosen randomly, for each animal at $200 \times$ magnification. In this evaluation, only ST in stage VII, according the acrosomic system (Russell et al. 1993), were considered. The cell counts were corrected for section thickness and nucleus or nucleolus diameter according to Abercrombie (1946) as modified by Amann (1962).

The total number of SCs per testis was estimated from the corrected counts of SC nucleoli per tubule cross-section and the total length of ST, according to Hochereau-de Reviers and Lincoln (1978). Following this calculation, and considering the testis net weight, the number of SCs per gram of testis was also determined. Regarding the spermatogenic and SC efficiencies, the ratio between corrected counts of round spermatids and SCs was calculated in 160-day-old rats. Since the duration of the SEC in Wistar rats is 13.3 days and the frequency of stage VII is around 18\% (Russell et al. 1993), the daily sperm production (DSP) per testis was calculated according to the following formula developed by França (1992): DSP = (total number of SCs per testis) $\times$ (the ratio of round spermatids per SCs at stage VII $) \times($ stage VII relative frequency $(\%)) /($ stage VII duration (days)).

\section{Quantification of apoptotic germ cells}

Germ cell apoptosis, which is easily recognized in histological sections embedded in plastic, was quantified in 40- and 160-day-old rats according to their typical morphological characteristics, such as cell shrinkage, formation of apoptotic bodies and chromatin condensation (Russell et al. 1993, Elmore 2007, de Alvarenga \& de França 2009). For all rats, germ cell apoptosis was determined in ten random ST crosssections, at stages VII-VIII of the SEC, and expressed as the total number of apoptotic cells per ST cross-section.

\section{Hormonal analyses and immunostaining}

In order to perform hormonal analysis for each animal, the blood samples $(0.3 \mathrm{~mL})$ were collected via cardiac puncture at 21, 40 and 160 days of age, when the animals were still anesthetized. The plasma was separated by centrifugation at $10,000 \mathrm{~g}$ for $10 \mathrm{~min}$ and stored at $-80^{\circ} \mathrm{C}$. Aiming to assess thyroid function and to check hypothyroidism treatment, the 
concentration of free T4 was measured by radioimmunoassay (RIA) kit from TECSA $®$ (Belo Horizonte, MG, Brazil), with sensitivity of $0.02 \mathrm{ng} / \mathrm{dL}$ and intra-assay and inter-assay coefficients of variation of 4.1 and $7.3 \%$, respectively.

For immunohistochemical staining, testicular samples were fixed for $24 \mathrm{~h}$ in methacarn at $4{ }^{\circ} \mathrm{C}$, dehydrated in ethanol and routinely embedded in paraplast. Serial sections $(5 \mu \mathrm{m}$ thick) were incubated overnight at $4^{\circ} \mathrm{C}$ with anti-KI67 (1:100 dilution; Pharmingen, \#550609, lot number 82421) and anti-P21 (1:100 dilution; Pharmingen, \#550827, lot number 54131). Reactions were visualized using biotin-conjugated secondary antibodies (1:200 dilution; Imuny, IC1M02, lot number 16160 ) in combination with Elite $A B C$ Kit (mixture of reagent A $(100 \mu \mathrm{L})$ and reagent $B(100 \mu \mathrm{L})$ into $5 \mathrm{~mL}$ of buffer; Vector Laboratories, CA, USA). Detection of signal was obtained via peroxidase substrate 3,39-diaminobenzidine (DAB, Sigma Aldrich) reaction and counterstaining with hematoxylin (Merck). In order to demonstrate the SC proliferation dynamics in the transition region after PTU treatment, a double immunofluorescence for KI67 (1:100 dilution; Pharmingen, \#550609, lot number 82421) and SOX9 (1:50 dilution; Santa Cruz Biotechnology, sc-20095, lot number H0715) was also performed. Reactions were visualized using Alexa-488 (antirabbit) and Alexa-633 (anti-mouse) conjugated secondary antibodies (1:200 dilution; Thermo Fisher Scientific) using a Nikon fluorescence microscope (Eclipse Ti).

After immunolabeling following standardized protocols (Ramos-Vara 2005), samples were photographed at 200× using Olympus microscope (BX60). SCs proliferation or differentiation were analyzed in the transition region and along the ST. The percentage of KI67 positive/negative SCs (evidence of proliferation) and of P21 positive/negative SCs (evidence of differentiation) were calculated per animal according to a previous study (Figueiredo et al. 2016). At least an area of $50,000 \mu^{2}$ (ranging from 5 to 10 tubular longitudinal sections) and 30 ST cross-sections were analyzed in the TR and along the ST, respectively. All the stained samples were analyzed for area and number of cells using the 'freehand' and 'cell counter' tools, respectively, in the image analysis software Image J v.1.45s (Image Processing and Analysis, in Java).

\section{Statistical analyses}

All data were tested for normality and homoscedasticity of the variances. Data were assessed by Student's $t$-test and were represented as the mean \pm S.E.M. (standard error of the mean). Data analyses were performed using the graphics and statistics program PRISM v5.0 (GraphPad Software, Inc). Differences were considered statistically significant at $P<0.05$.

\section{Results \\ Biometric data}

The BW measured throughout the experiment are shown in Fig. 2. As it can be observed, the BW in both groups was similar during the first 2 weeks of PTU treatment, but were significantly lower $(P<0.05)$ in treated rats only when they reached 40 days of age (Table 1 ), i.e. at the end of the treatment period. This significant

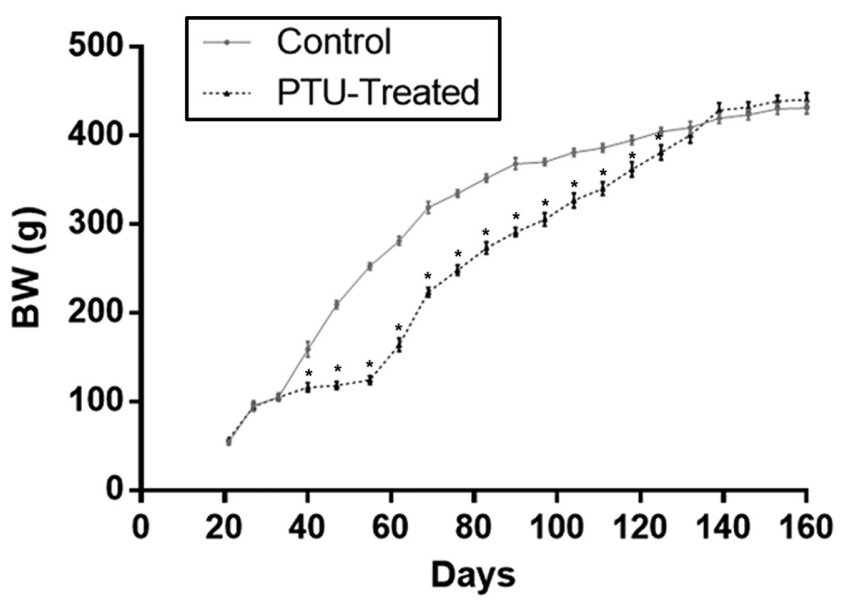

Figure 2 Evaluation of body weight (BW) throughout the experimental period. Significant differences (Student's $t$-test, $P<0.05$ ) were observed at the end of PTU treatment (40 days) and continued until the animals were almost 20 weeks old.

difference lasted until 3 weeks ( 140 days of age) before the animals were killed and, after that, in comparison to the controls, the BW of treated rats recovered totally (Table 2).

\section{Thyroid gland and hormonal analyses}

At 21 days of age, as expected, the thyroid gland was normal, with variable sized follicles filled with thyroid colloid and having a mean lumen diameter of $55 \mu \mathrm{m}$ (Fig. 3A and G). At the end of PTU treatment, most thyroid glands follicles in treated rats were devoid of colloid (Fig. 3C) and, in comparison to the controls, the follicular lumen diameter was significantly reduced $(16 \mu \mathrm{m}$ vs $60 \mu \mathrm{m}$, Fig. 3G). On day 160 , both groups exhibited normal and similar thyroid gland histology with follicular lumen diameter measuring in average $70 \mu \mathrm{m}$ (Fig. 3D, E and G). Confirming the efficacy of the treatment and the histological evaluation, on day 40 the free T4 level was drastically reduced $(P<0.05)$ in the treated group (Fig. 3F). As expected because thyroid gland histology was normal, adult rat T4 plasmatic levels were quite similar in both investigated groups $(P<0.05)$.

\section{Quantitative and qualitative testis evaluation}

Regarding the key testicular parameters quantitatively evaluated, in comparison to the controls at 40 days of age, PTU-treated rats showed reduced $(p<0.05)$ TW, tubular diameter and seminiferous tubule volume. In contrast, the results obtained for several parameters such as the number of SCs per testis and testis gram, the number of apoptotic germ cells per ST cross-sections (Supplementary Fig. 1, see section on supplementary data given at the end of this article) and the transition region individual length were increased $(p<0.05)$ 
Table 1 Biometric and morphometric data from control and PTU-treated Wistar rats at 40 days of age (mean \pm S.E.M.).

\begin{tabular}{lcc}
\hline Parameter & Control $(n=8)$ & PTU $(n=8)$ \\
\hline Body weight $(\mathrm{g})$ & $159 \pm 4$ & $116 \pm 2^{*}$ \\
Testis weight $(\mathrm{mg})$ & $702 \pm 53$ & $471 \pm 40^{*}$ \\
Gonadosomatic index $(\%)$ & $0.88 \pm 0.05$ & $0.81 \pm 0.11$ \\
Tubular diameter $(\mu \mathrm{m})$ & $266 \pm 16$ & $221 \pm 7^{*}$ \\
Percentage of seminiferous tubules $(\%)$ & $90.5 \pm 0.9$ & $92.1 \pm 1.4$ \\
Volume of seminiferous tubules $(\mathrm{mL})$ & $0.61 \pm 0.06$ & $0.42 \pm 0.04^{*}$ \\
Individual length of transition region $(\mu \mathrm{m})$ & $226 \pm 9.8$ & $260 \pm 3.6^{*}$ \\
Total length of seminiferous tubules $(\mathrm{m})$ & $11.1 \pm 0.6$ & $10.9 \pm 0.6$ \\
Sertoli cell per testis $\left(\times 10^{6}\right)$ & $34.2 \pm 0.6$ & $39.9 \pm 0.9^{*}$ \\
Sertoli cell/gram/testis $\left(\times 10^{6}\right)$ & $53.5 \pm 6.4$ & $91.3 \pm 3.5^{*}$ \\
Round spermatids per Sertoli cell & $5.8 \pm 0.6$ & $4.9 \pm 0.4$ \\
Apoptotic germ cells per tubular cross-section & $0.8 \pm 0.2$ & $1.8 \pm 0.3^{*}$ \\
\hline
\end{tabular}

*Statistically significant $(P<0.05)$.

in treated animals. Also, at this age, no significant differences were observed for the gonadosomatic index, the ST total length and the number of round spermatids per SC (Table 1). However, the qualitative evaluation showed that, at the end of treatment, spermatogenesis was delayed in treated rats (Fig. 4G and $\mathrm{H}$ ).

Confirming that the treated rats recovered totally from the hypothyroidism by the end of the experimental period, the data found for most parameters evaluated were similar in both groups at 160 days of age (Table 2). However, the results obtained for several very important parameters related to sperm production, such as TW, the ST volume, the ST total length and SCs per testis, were significantly higher $(P<0.05)$ in rats treated with PTU, which reflected a much higher DSP per testis $(\sim 30 \%)$ in these animals (Table 2). As a result of similar BW and augmented TW, the GSI was increased $(P<0.05)$ in PTU-treated rats (Table 2). Histologically, no differences were observed in the testicular parenchyma, including the transition region in both adult groups evaluated (Fig. 4). It is worth mentioning that at both 40 and 160 days of age, the number of SCs was increased significantly $(P<0.05)$ in the treated males compared to the control rats.

\section{Immunostaining evaluation}

To assess the potential effects of transient hypothyroidism on SCs proliferation the number of KI67 staining cells were evaluated (Fig. 5). SCs in the transition region showed nearly 5-fold greater $\mathrm{KI} 67$ positive SCs in the PTU-treated compared to controls $(18.4 \%$ versus $3.7 \%$, respectively). However, on day 160 , there was no difference between the groups in SC proliferation (Fig. 5). Most importantly, seminiferous tubule areas outside the TR, in both controls and PTU-treated testes, showed no proliferative SCs at 21,40 or 160 days of age (Supplementary Fig. 2A, B, C, D and E). To estimate the number of differentiated SCs in the transition region, the number of SCs with P21 labeling were assessed (Fig. 6). On day 40 , at the end of the treatment period, TRSCs in the PTU-treated males had a significant reduction in P21 staining (80.9\%) compared to controls (88.3\%), indicating that a higher population of immature SCs was present in the treated group. However, on day 160 , there was no difference in SC differentiation, with both groups showing approximately 90\% labeling for P21 (Fig. 6). To confirm the specific labeling of SCs in the transition region, SOX9, a specific marker for SCs, was used in

Table 2 Biometric and morphometric data from control and PTU-treated Wistar rats at 160 days of age (mean \pm S.E.M.).

\begin{tabular}{lcc}
\hline Parameter & Control $(n=8)$ & PTU $(n=8)$ \\
\hline Body weight $(\mathrm{g})$ & $431 \pm 3$ & $440 \pm 3$ \\
Testis weight $(\mathrm{g})$ & $1.58 \pm 0.03$ & $1.81 \pm 0.03^{*}$ \\
Gonadosomatic index $(\%)$ & $0.73 \pm 0.02$ & $0.82 \pm 0.02^{*}$ \\
Tubular diameter $(\mu \mathrm{m})$ & $334 \pm 5$ & $336 \pm 2$ \\
Percentage of seminiferous tubules $(\%)$ & $89.6 \pm 1.4$ & $89.5 \pm 0.7$ \\
Volume of seminiferous tubules $(\mathrm{mL})$ & $1.32 \pm 0.02$ & $1.51 \pm 0.02^{*}$ \\
Individual length of transition region $(\mu \mathrm{m})$ & $317 \pm 13$ & $329 \pm 15$ \\
Total length of seminiferous tubules $(\mathrm{m})$ & $15.2 \pm 0.4$ & $17.1 \pm 0.3^{*}$ \\
Sertoli cell per testis $\left(\times 10^{6}\right)$ & $36.5 \pm 1.5$ & $42.7 \pm 1.8^{*}$ \\
Sertoli cell/gram/testis $\left(\times 10^{6}\right)$ & $24.7 \pm 0.9$ & $25.2 \pm 0.9$ \\
Round spermatids per Sertoli cell & $9.2 \pm 0.3$ & $10.0 \pm 0.3$ \\
Apoptotic germ cells per tubular cross-section & $1.0 \pm 0.2$ & $1.0 \pm 0.3$ \\
Daily sperm production per testis $\left(\times 10^{6}\right)$ & $25.6 \pm 1.1$ & $32.8 \pm 1.2^{*}$ \\
Daily sperm production/gram/testis $\left(\times 10^{6}\right)$ & $17.3 \pm 0.6$ & $19.4 \pm 0.6$ \\
\hline
\end{tabular}

*Statistically significant $(P<0.05)$.

$N=$ number of rats. 


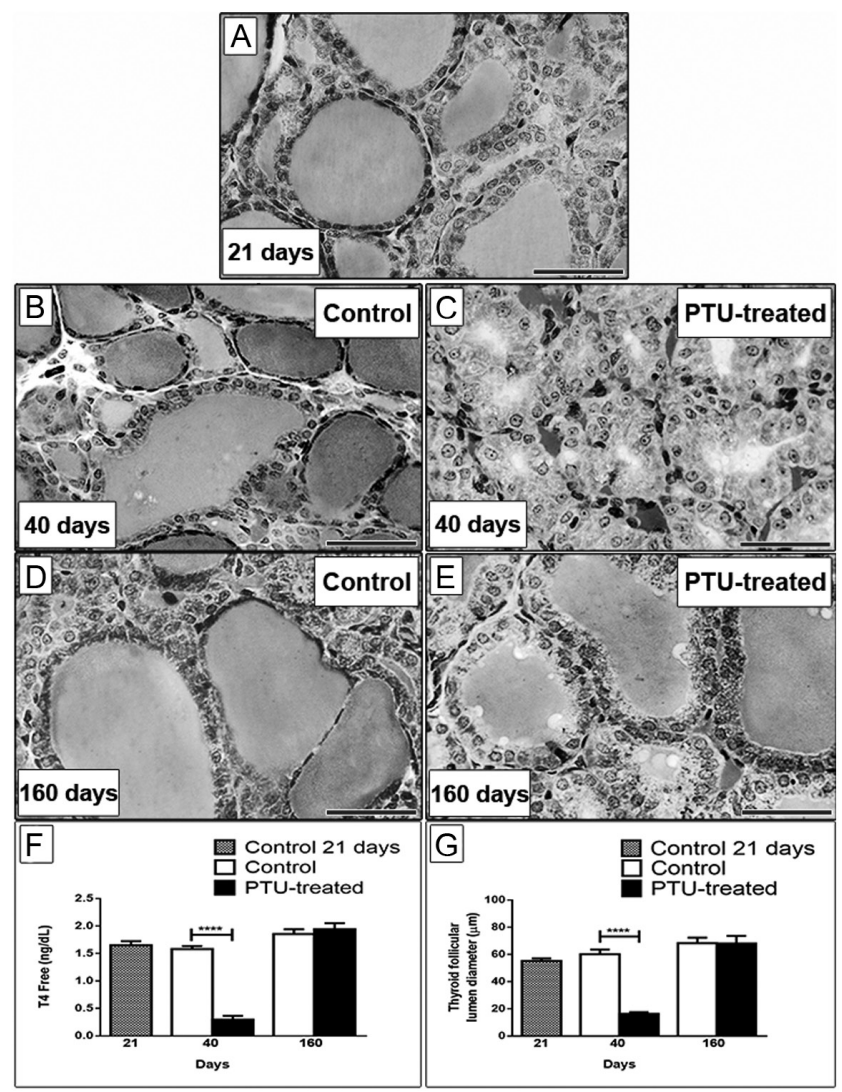

Figure 3 Free T4 blood plasma levels and thyroid gland histomorphometric evaluation (A, B, C, D, E, F and G). In 21-day-old rats, thyroid glands exhibited characteristic histology, having variablesized follicles filled with thyroid colloid (A). At the end of PTU treatment (on day 40), thyroid gland follicles in controls (B) remained filled with colloid, but in treated rats the follicles differed significantly, as most follicles had no colloid (C). At the end of the experimental period (on day 160), the thyroid gland histology was normal in both groups (D and E). T4 levels (F) and thyroid follicular lumen diameters $(\mathrm{G})$ were significantly reduced (Student's $t$-test, $P<0.05)$ in treated rats only on day 40 . Bar: $50 \mu \mathrm{m}$.

double-staining with KI67, the marker for proliferation (Fig. 7).

\section{Discussion}

The present study uncovered two major findings regarding Sertoli cell proliferation in the rat: (a) transient hypothyroidism during the prepubertal period (2140 days of age) induced SC proliferation by day 160 and (b) this stimulation of SC proliferation occurred only in the transitional regions, which are the terminal ends of the seminiferous tubule, connecting to the rete testis (Perey et al. 1961, Hermo \& Dworkin 1988). Previous studies concluded that to increase testis weight, transient hypothyroidism could not begin after day 8 post birth, as treatment during the prepubertal period (days 24-48) had no effect on testis weight by day 90 (Cooke et al. 1992). However, based on data from the present study,
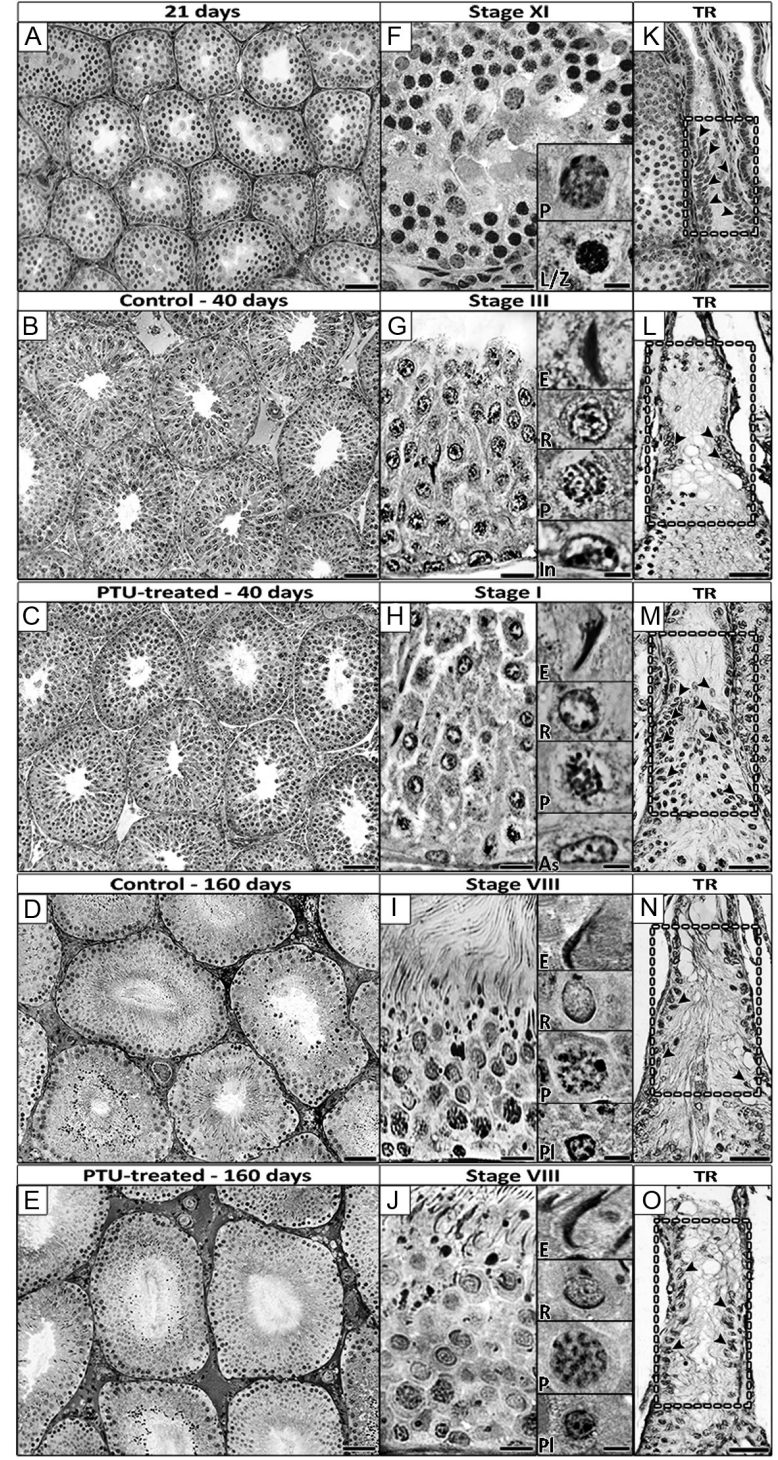

Figure 4 Histological appearance of the seminiferous tubules (ST) at different magnifications ( $A, B, C, D, E, F, G, H, I$ and $J)$ and its transition region ( $K, L, M, N$ and $O$ ) in all three investigated ages. The inserts represent the most advanced germ cell type/germ cells association. At 21 days of age, the ST diameters were much smaller (A) and pachytene spermatocyte were in association with leptotene/ zygotene cells $(\mathrm{F})$, presumably in stage $\mathrm{XI}$ of the seminiferous epithelium cycle (SEC). On day 40, in comparison with treated rats (C) and as expected, spermatogenesis was more advanced in the control testis (G), in which elongated spermatids in stage III of the SEC were present, and the ST diameters were slightly larger (B). At 160 days, spermatogenesis was complete in both groups and all cellular associations were similar in control ( $D$ and $I)$ and treated rats (E and J). In the transition region (dotted white line rectangle), Sertoli cell (black arrowheads) density in 21-day-old control rats (K) was similar to that seen in the 40-day-old PTU-treated rats (M), whereas the controls showed a reduced density on day 40 (L). As, type A spermatogonia; E, elongated spermatids; In, type intermediate spermatogonia; $L / Z$, leptotene in transition to zygotene spermatocytes; $\mathrm{P}$, pachytene spermatocytes; PI, pre-leptotene spermatocytes; R, round spermatids. Bar: $50 \mu \mathrm{m}(\mathrm{A}, \mathrm{B}, \mathrm{C}, \mathrm{D}$ and $\mathrm{E} ; \mathrm{K}$, $\mathrm{L}, \mathrm{M}, \mathrm{N}$ and $\mathrm{O}) ; 20 \mu \mathrm{m}$ (F, G, H, I and J); $5 \mu \mathrm{m}$ (Inserts). 


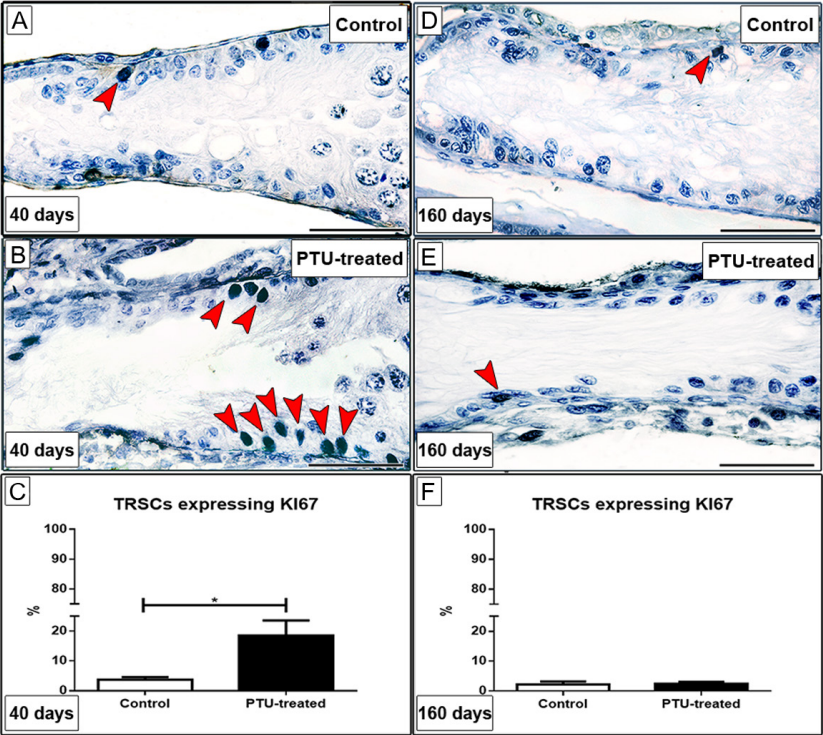

Figure 5 Immunostaining for proliferation of transition region Sertoli cells (TRSCs), using anti-KI67, in control and PTU-treated rats on days $40(A, B$ and $C)$ and 160 (D, E and F). The number of mitotic SCs (red arrowheads) was approximately five-fold higher (Student's $t$-test, $P<0.05)$ at the end of PTU treatment $(\mathrm{C})$. In adult rats, proliferation was quite low and similar in both groups $(\mathrm{F})$. Bar: $50 \mu \mathrm{m}$.

it is possible that the previous study would have found an increase, if the study had observed weights out to day 160. Transient neonatal PTU treatment from birth to day 25 showed continuous increases in testis weight and DSP from day 90 to 160 (Cooke et al. 1991).

In comparison to former studies involving PTU treatment (Cooke et al. 1991, 1992, Joyce et al. 1993), low dosages of PTU $(<0.1 \% \mathrm{w} / \mathrm{v})$ induce faster testis maturation due to the more rapid return to euthyroidic status, which is critical to enhance SC proliferation and testis growth (Cooke et al. 1993, Rijntjes et al. 2017). Cooke and colleagues (1993) previously demonstrated that PTU doses, ranging from 0.006 to $0.1 \%(\mathrm{w} / \mathrm{v})$, are quite effective in significantly suppressing T4 concentrations. The $0.03 \%(\mathrm{w} / \mathrm{v})$ PTU dose administered in the present work was 5 -fold higher than the lowest effective dose used previously (Cooke et al. 1993) and treatment was direct via water in the present study, versus the mother's milk in the Cooke study. Efficacy of the $0.03 \%(\mathrm{w} / \mathrm{v})$ PTU dosage was confirmed as a sensitive method to increase testis mass by the observed reduction in thyroxin levels at the end of the treatment period. Just after PTU treatment, although an initial reduction in testis mass was observed, the number of Sertoli cells per testis was increased at day 40. Similar findings were obtained by Rijntjes et al. (2009), treating dams with an iodide-poor diet and evaluating pups that maintained the hypothyroid condition until euthanasia. In PTU-treated rats evaluated on day 160, the increased testis size and function are attributed to the timing of return to the euthyroid condition and also to the

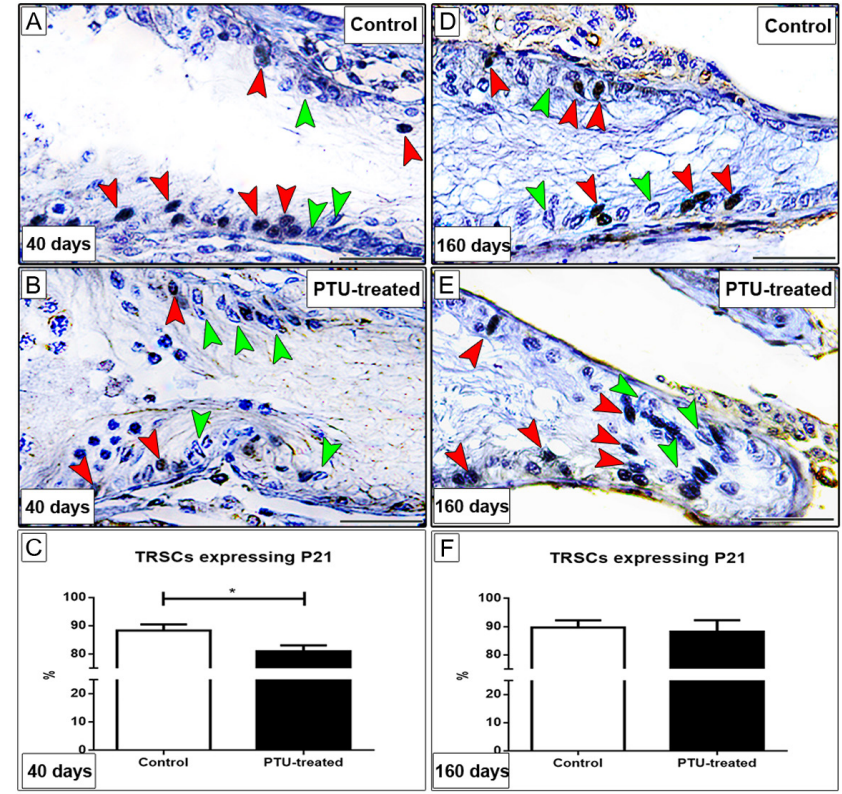

Figure 6 Immunostaining for differentiation of transition region Sertoli cells (TRSCs), using anti-P21 in control and PTU-treated rats on days 40 (A, B and C) and 160 (D, E and F). The number of mature SCs (red arrowheads) was significantly lower (Student's $t$-test, $P<0.05$ ) at the end of PTU treatment (C). In adult rats, the number of SCs expressing this cell-cycle inhibitor was approximately $90 \%$ and similar in both experimental groups. Bar: $50 \mu \mathrm{m}$.

lower dosage of PTU which would allow more rapid maturation of the testis, due to a more rapid return to euthyroidism after cessation of treatment (Cooke et al. 1993, Rijntjes et al. 2017).

The transition region is only a small area of the seminiferous tubule terminal ends, but the epithelium is packed with modified, immature SCs that are mitotically active even in the adult (Hermo \& Dworkin 1988, Figueiredo et al. 2016, Kulibin \& Malolina 2016, Malolina \& Kulibin 2017). Early studies on the proliferation of rat SCs concluded that SC division stopped between day 16 and 21 post birth (Orth 1982, Van Haaster et al. 1993). This supposition was of course correct, but only if the observations were made within the parenchyma or body of the testis, which would occur in routine sectioning for histology, as it has always been common to use a midline, transverse plane of section. However, in rodents, the exit of the transition region and rete testis does not occur in the mid-region, but rather leaves the testis off center and more cephalic (La et al. 2012, Ford et al. 2014, Nakata 2019), requiring specific and careful sectioning to study. Thus, the discovery that SCs in this region are capable of proliferation was rather significant, in light of the past and present studies of transient hypothyroidism, as only in this unique region were SCs found to be proliferating in adult testes, in both controls and treated males, but significantly increased after PTU treatment. 

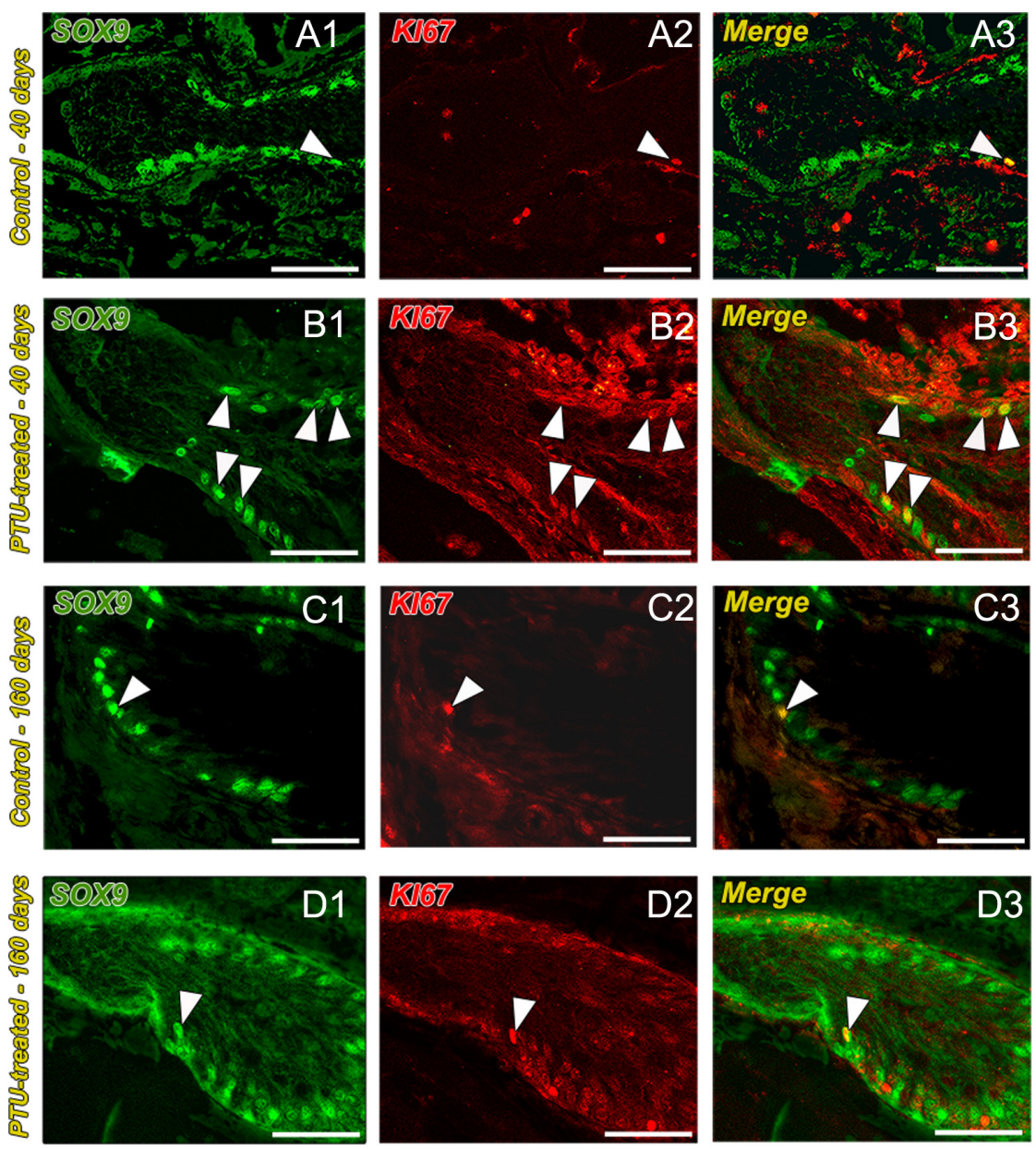

Figure 7 Double immunofluorescence staining for SOX9, a Sertoli cell marker (A1-D1) and KI67, a proliferation marker (A2-D2) in the transition region of control and PTU-treated rats on days 40 (A1-B3) and 160 (C1-D3). The number of mitotic Sertoli cells (SCs; white arrowheads) were noticeably increased (B3) at the end of PTU treatment. In adult rats, few SCs (blue arrowheads) were seen proliferating in both experimental groups (C3, D3). Bar: $50 \mu \mathrm{m}$.

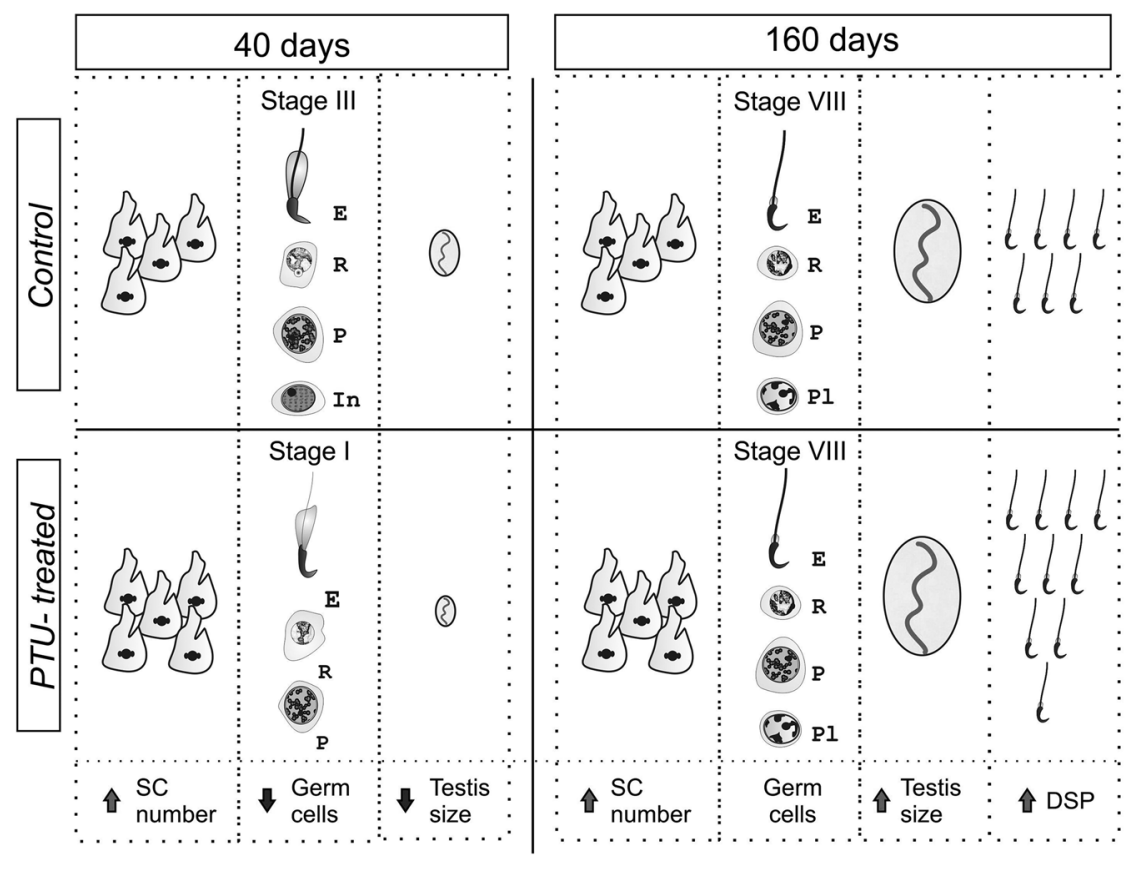

Figure 8 Schematic illustration summarizing the main results. On day 40, although delayed spermatogenesis was observed in PTU-treated rats, in comparison to the control group, the number of Sertoli cells (SC) was significantly higher. On day 160, all the key testis parameters evaluated, such as testis weight, SC number and the daily sperm production per testis (DSP), were significantly higher in rats that underwent the PTU treatment. 
This study corroborates our recent data showing that TRSCs have considerable mitotic activity from 36 to 120 days of age, even in control rats (Figueiredo et al. 2016). It is interesting that SCs away from the transition region did not show evidence of proliferation in adult rats, but in normal men, after gonadotropin suppression and in tubules from men with seminoma, SCs do show an induced capacity to proliferate (Tarulli et al. 2012, 2013). However, the major difference between the present study in rats and those showing SC proliferation in men is the immature status of SCs in the transition region only in adult rats (Figueiredo et al. 2016), with or without the PTU treatment, while in men SCs in the testis parenchyma appear not to be terminally differentiated and thus are capable of responding to gonadotropin suppression with de-differentiation and proliferation (Tarulli et al. 2012, 2013). TW and sperm production increase markedly in pigs after puberty (around four months and extending up to four years of age), without any significant increase in tubular diameter and SC efficiency (Swierstra 1973, França et al. 2000, Avelar et al. 2010), which suggests that testicular growth after puberty may involve primarily the terminal regions of the seminiferous tubules. The importance of SC plasticity in the transition region of men and large mammals remains to be determined.

In conclusion, based on the already known proliferative capacity of TRSCs (Figueiredo et al. 2016, Kulibin \& Malolina 2016) and using prepubertal PTU treatment, we were able to significantly increase several key testis parameters related to sperm production in adult rats such as TW, SCs number and DSP (Fig. 8). Thus, the transition region is a unique testis site for investigating both spermatogonial niche formation (Aiyama et al. 2015), as well as SC proliferation in the adult male, the potential interactions and regulation of these two niche cell populations. Possible implications of these findings for clinical and therapeutic applications in male infertility should be investigated.

\section{Supplementary data}

This is linked to the online version of the paper at https://doi.org/10.1530/REP-19-0127.

\section{Declaration of interest}

The authors declare that there is no conflict of interest that could be perceived as prejudicing the impartiality of the research reported.

\section{Funding}

This work was supported by the National Council for Scientific and Technological Development $(\mathrm{CNPq})$, Foundation to Support Research from the State of Minas Gerais (FAPEMIG), and financed in part by the Coordination for the Improvement of Higher Education Personnel - Brazil (CAPES; Finance Code 001) and PRPq-UFMG.

\section{Acknowledgements}

Technical help from Mara Lívia Santos is highly appreciated. The support from Federal University of Minas Gerais (UFMG) and Image Acquisition and Processing Center (CAPI-ICB/ UFMG) were of great importance.

\section{References}

Abercrombie M 1946 Estimation of nuclear populations from microtome sections. Anatomical Record 94 239-247. (https://doi.org/10.1002/ ar.1090940210)

Aiyama Y, Tsunekawa N, Kishi K, Kawasumi M, Suzuki H, Kanai-Azuma M, Kurohmaru M \& Kanay Y 2015 A niche for GFR $\alpha 1$-positive spermatogonia in the terminal segments of the seminiferous tubules in hamster testes. Stem Cells 33 2811-2824. (https://doi.org/10.1002/stem.2065)

Almirón I \& Chemes H 1988 Spermatogenic onset. II. FSH modulates mitotic activity of germ and Sertoli cells in immature rats. International Journal of Andrology 11 235-246. (https://doi.org/10.1111/j.1365-2605.1988. tb00998.x)

Amann RP 1962 Reproductive capacity of dairy bulls. III. The effect of ejaculation frequency, unilateral vasectomy, and age on spermatogenesis. American Journal of Anatomy 110 49-67. (https://doi.org/10.1002/ aja.1001100106)

Attal J, Courot M, Richetin C \& Pisselet C 1963 Developpement testiculaire et etablissement de la spermatogeneses chez le taureau. Annales de Biologie Animale Biochimie Biophysique 3 219-241. (https:// doi.org/10.1051/rnd:19630302)

Auharek SA \& França LR 2010 Postnatal testis development, Sertoli cell proliferation and number of different spermatogonial types in C57BL/6) mice made transiently hypo- and hyperthyroidic during the neonatal period. Journal of Anatomy 216 577-588. (https://doi.org/10.1111/ j.1469-7580.2010.01219.x)

Avelar GF, Oliveira CF, Soares JM, Silva IJ, Dobrinski I, Hess RA \& França LR 2010 Postnatal somatic cell proliferation and seminiferous tubule maturation in pigs: a non-random event. Theriogenology $\mathbf{7 4}$ 11-23. (https://doi.org/10.1016/j.theriogenology.2009.12.014)

Cooke PS, Hess RA, Porcelli J \& Meisami E 1991 Increased sperm production in adult rats after transient neonatal hypothyroidism. Endocrinology $\mathbf{1 2 9}$ 244-248. (https://doi.org/10.1210/endo-129-1-244)

Cooke PS, Porcelli J \& Hess RA 1992 Induction of increased testis growth and sperm production in adult rats by neonatal administration of the goitrogen propyithiouracil (PTU): the critical period. Biology of Reproduction 46 146-154. (https://doi.org/10.1095/biolreprod46.1.146)

Cooke PS, Kirby JD \& Porcelli J 1993 Increased testis growth and sperm production in adult rats following transient neonatal goitrogen treatment: optimization of the propylthiouracil dose and effects of methimazole. Journal of Reproduction and Fertility 97 493-499. (https://doi. org/10.1530/jrf.0.0970493)

Cooke PS, Hess RA \& Kirby JD 1994 A model system for increasing testis size and sperm production: potential application to animal science. Journal of Animal Science 72 43-54. (https://doi.org/10.2527/1994.72suppl_343x)

Cooke PS, Holsberger DR \& França LR 2005 Thyroid hormone regulation of Sertoli cell development. In Sertoli Cell Biology, pp 217-226. Eds MK Skinner \& MD Griswold. San Diego, CA: Elsevier Academic Press.

Crofton KM \& Zoeller RT 2005 Mode of action: neurotoxicity induced by thyroid hormone disruption during development - hearing loss resulting from exposure to PHAHs. Critical Reviews in Toxicology 35 757-769. (https://doi.org/10.1080/10408440591007304)

de Alvarenga ER \& de França LR 2009 Effects of different temperatures on testis structure and function, with emphasis on somatic cells, in sexually mature Nile tilapias (Oreochromis niloticus). Biology of Reproduction $\mathbf{8 0}$ 537-544. (https://doi.org/10.1095/biolreprod.108.072827)

Dong BJ 2006. In Textbook of Therapeutics: Drug and Disease Management. Eds RA Helms \& DJ Quan. Philadelphia, PA: Lippincott Williams \& Wilkins. 
Elmore S 2007 Apoptosis: a review of programmed cell death. Toxicologic Pathology 35 495-516. (https://doi.org/10.1080/01926230701320337)

Figueiredo AFA, França LR, Hess RA \& Costa GMJ 2016 Sertoli cells are capable of proliferation into adulthood in the transition region between the seminiferous tubules and the rete testis in Wistar rats. Cell Cycle 15 2486-2496. (https://doi.org/10.1080/15384101.2016. 1207835)

Ford Jr J, Carnes K \& Hess RA 2014 Ductuli efferentes of the male golden Syrian hamster reproductive tract. Andrology 2 510-520. (https://doi. org/10.1111/j.2047-2927.2014.00194.x)

França LR 1991 Análise morfofuncional da espermatogênese de suínos adultos da raça Piau. Thesis. Belo Horizonte, Brazil: Federal University of Minas Gerais.

França LR 1992 Daily sperm production in Piau boars estimated from Sertoli cell population and Sertoli cell index. In Proceedings of the 12th International Congress on Animal Reproduction and Artificial Insemination. Ed SJ Dieleman. Netherlands: Elsevier Science.

França LR, Hess RA, Cooke PS \& Russell LD 1995 Neonatal hypothyroidism causes delayed Sertoli cell maturation in rats treated with propylthiouracil: evidence that the Sertoli cell controls testis growth. Anatomical Record 242 57-69. (https://doi.org/10.1002/ar.1092420108)

França LR, Silva Jr VA, Chiarini-Garcia H, Garcia SK \& Debeljuk L 2000 Cell proliferation and hormonal changes during postnatal development of the testis in the pig. Biology of Reproduction 63 1629-1636. (https:// doi.org/10.1095/biolreprod63.6.1629)

França LR, Hess RA, Dufour JM, Hofmann MC \& Griswold MD 2016 The Sertoli cell: one hundred fifty years of beauty and plasticity. Andrology 4 189-212. (https://doi.org/10.1111/andr.12165)

Gutvirtz G, Walfisch A, Wainstock T, Landau D \& Sheiner E 2019 Maternal hypothyroidism and future pediatric neurological morbidity of the offspring. Archives of Gynecology and Obstetrics 299 975-981. (https:// doi.org/10.1007/s00404-019-05092-1)

Hermo L \& Dworkin J 1988 Transitional cells at the junction of seminiferous tubules with the rete testis of the rat: their fine structure, endocytic activity, and basement membrane. American Journal of Anatomy 181 111-131. (https://doi.org/10.1002/aja.1001810202)

Hess RA \& França LR 2007 Spermatogenesis and cycle of the seminiferous epithelium. In Molecular Mechanisms in Spermatogenesis. Ed CY Cheng. New York: Landes Bioscience. (https://doi.org/10.1007/978-0-38709597-4_1)

Hess RA, Cooke PS, Bunick DA \& Kirby JD 1993 Adult testicular enlargement induced by neonatal hypothyroidism is accompanied by increased Sertoli and germ cell numbers. Endocrinology 132 2607-2613. (https://doi.org/10.1210/endo.132.6.8504761)

Hochereau-de Reviers MT \& Lincoln GA 1978 Seasonal variation in the histology of the testis of the red deer, Cervus elaphus. Journal of Reproduction and Fertility 54 209-213. (https://doi.org/10.1530/ jrf.0.0540209)

Holsberger DR \& Cooke PS 2005 Understanding the role of thyroid hormone in Sertoli cell development: a mechanistic hypothesis. Cell and Tissue Research 322 133-140. (https://doi.org/10.1007/s00441-0051082-z)

Johnson L \& Neaves WB 1981 Age-related changes in the Leydig cell population, seminiferous tubules and sperm production in stallions. Biology of Reproduction 24 703-712. (https://doi.org/10.1095/ biolreprod24.3.703)

Johnson L, Petty CS \& Neaves WB 1981 A new approach to quantification of spermatogenesis and its application to germinal cell attrition during human spermiogenesis. Biology of Reproduction 25 217-226. (https:// doi.org/10.1095/biolreprod25.1.217)

Joyce KL, Porcelli J \& Cooke PS 1993 Neonatal goitrogen treatment increases adult testis size and sperm production in the mouse. Journal of Andrology 14 448-455. (https://doi.org/10.1002/j.1939-4640.1993. tb03261.x)

Kulibin AY \& Malolina EA 2016 Only a small population of adult Sertoli cells actively proliferates in culture. Reproduction 152 271-281. (https:// doi.org/10.1530/REP-16-0013)

La DK, Creasy DM, Hess RA, Baxter E, Pereira ME, Johnson CA, Vinken P \& Snook SS 2012 Efferent duct toxicity with secondary testicular changes in rats following administration of a novel leukotriene A4 hydrolase inhibitor. Toxicologic Pathology 40 705-714. (https://doi. org/10.1177/0192623312441412)
Lucas TF, Nascimento AR, Pisolato R, Pimenta MT, Lazari MF \& Porto CS 2014 Receptors and signaling pathways involved in proliferation and differentiation of Sertoli cells. Spermatogenesis 4 e28138. (https://doi. org/10.4161/spmg.28138)

Magre S \& Jost A 1991 Sertoli cells and testicular differentiation in the rat fetus. Journal of Electron Microscopy Technique 19 172-188. (https:// doi.org/10.1002/jemt.1060190205)

Malolina EA \& Kulibin AY 2017 Rete testis and the adjacent seminiferous tubules during postembryonic development in mice. Russian Journal of Developmental Biology 48 385-392. (https://doi.org/10.1134/ S1062360417060029)

Meachem SJ, Ruwanpura SM, Ziolkowski J, Ague JM, Skinner MK \& Loveland KL 2005 Developmentally distinct in vivo effects of FSH on proliferation and apoptosis during testis maturation. Journal of Endocrinology 186 429-446. (https://doi.org/10.1677/joe.1.06121)

Nakata H 2019 Morphology of mouse seminiferous tubules. Anatomical Science International 94 1-10. (https://doi.org/10.1007/s12565-0180455-9)

Nicholls PK, Harrison CA, Rainczuk KE, Vogl AW \& Stanton PG 2013 Retinoic acid promotes Sertoli cell differentiation and antagonises activin-induced proliferation. Molecular and Cellular Endocrinology 377 33-43. (https://doi.org/10.1016/j.mce.2013.06.034)

Orth JM 1982 Proliferation of Sertoli cells in fetal and postnatal rats: a quantitative autoradiographic study. Anatomical Record 203 485-492. (https://doi.org/10.1002/ar.1092030408)

Orth JM 1984 The role of follicle-stimulating hormone in controlling Sertoli cell proliferation in testes of fetal rats. Endocrinology 115 1248-1255. (https://doi.org/10.1210/endo-115-4-1248)

Orth JM, Gunsalus GL \& Lamperti AA 1988 Evidence from Sertoli celldepleted rats indicates that spermatid number in adults depends on numbers of Sertoli cells produced during perinatal development. Endocrinology 122 787-794. (https://doi.org/10.1210/endo-122-3-787)

Perey B, Clermont Y \& Leblond CP 1961 The wave of the seminiferous epithelium in the rat. American Journal of Anatomy 108 47-77. (https:// doi.org/10.1002/aja.1001080105)

Rajab NMA, Ukropina M \& Cakic-Milosevic M 2017 Histological and ultrastructural altertaions of rat thyroid gland after short-term treatment with high doses of thyroid hormones. Saudi Journal of Biological Sciences 24 1117-1125. (https://doi.org/10.1016/j.sjbs.2015.05.006)

Ramos-Vara JA 2005 Technical aspects of immunohistochemistry. Veterinary Pathology 42 405-426. (https://doi.org/10.1354/vp.42-4-405)

Rijntjes E, Swarts HJ, Anand-Ivell R \& Teerds KJ 2009 Prenatal induced chronic dietary hypothyroidism delays but does not block adult-type Leydig cell development. American Journal of Physiology: Endocrinology and Metabolism $296 \quad$ E305-E314. (https://doi.org/10.1152/ ajpendo.90750.2008)

Rijntjes E, Gomes MLM, Zupanič N, Swarts HJM, Keijer J \& Teerds KJ 2017 Transient hypothyroidism: dual effect on adult-type Leydig cell and Sertoli cell development. Frontiers in Physiology 8323 . (https://doi. org/10.3389/fphys.2017.00323)

Roosen-Runge EC 1961 The rete testis in the albino rat: its structure, development and morphological significance. Acta Anatomica 45 1-30. (https://doi.org/10.1159/000141738)

Rotgers E, Jørgensen A \& Yao HH 2018 At the crossroads of fate-somatic cell lineage specification in the fetal gonad. Endocrine Reviews 39 739-759. (https://doi.org/10.1210/er.2018-00010)

Russell LD, Ettlin RA, Sinha-Hikim AP \& Clegg ED 1993 Histological and Histopathological Evaluation of the Testis. International Journal of Andrology 16 83. (https://doi.org/10.1111/j.1365-2605.1993.tb01156.x)

Sharpe RM 1994 Regulation of spermatogenesis. In The Physiology of Reproduction. Eds E Knobil \& JD Neil. New York: Raven Press. (https:// doi.org/10.1111/j.1439-0272.1994.tb00816.x)

Shiroozu A, Taurog A, Engler H \& Dorris ML 1983 Mechanism of action of thioureylene antithyroid drugs in the rat: possible inactivation of thyroid peroxidase by propylthiouracil. Endocrinology 113 362-370. (https:// doi.org/10.1210/endo-113-1-362)

Sun Y, Yang W, Luo H, Wang X, Chen Z, Zhang J, Wang Y \& Li X 2015 Thyroid hormone inhibits the proliferation of piglet Sertoli cell via PI3K signaling pathway. Theriogenology 83 86-94. (https://doi.org/10.1016/j. theriogenology.2014.08.003)

Svingen T \& Koopman P 2013 Building the mammalian testis: origins, differentiation, and assembly of the component cell populations. 
Genes and Development 27 2409-2426. (https://doi.org/10.1101/ gad.228080.113)

Swierstra EE 1973 Influence of breed, age, and ejaculation frequency on boar semen composition. Canadian Journal of Animal Science 53 43-53. (https://doi.org/10.4141/cjas73-006)

Tarulli GA, Stanton PG \& Meachem SJ 2012 Is the adult Sertoli cell terminally differentiated? Biology of Reproduction 87 13.1-13.11. (https://doi.org/10.1095/biolreprod.111.095091)

Tarulli GA, Stanton PG, Loveland KL, Meyts ER, McLachlan RI \& Meachem SJ 2013 A survey of Sertoli cell differentiation in men after gonadotropin suppression and in testicular cancer. Spermatogenesis 3 e24014. (https://doi.org/10.4161/spmg.24014)

Taurog A, Riesco G \& Larsen PR 1976 Formation of 3,3'-diiodothyronine and $3^{\prime}, 5^{\prime}, 3$-triiodothyronine (reverse T3) in thyroid glands of rats and in enzymatically iodinated thyroglobulin. Endocrinology 99 281-290. (https://doi.org/10.1210/endo-99-1-281)

Van Haaster LH, De Jong FH, Docter ROEL \& De Rooij DG 1992 The effect of hypothyroidism on Sertoli cell proliferation and differentiation and hormone levels during testicular development in the rat. Endocrinology 131 1574-1576. (https://doi.org/10.1210/endo.131.3.1505485)
Van Haaster LH, De Jong FH, Docter ROEL \& De Rooij DG 1993 High neonatal triiodothyronine levels reduce the period of Sertoli cell proliferation and accelerate tubular lumen formation in the rat testis, and increase serum inhibin levels. Endocrinology 133 755-760. (https:// doi.org/10.1210/endo.133.2.8344214)

Wagner MS, Wajner SM \& Maia AL 2008 The role of thyroid hormone in testicular development and function. Journal of Endocrinology 199 351-365. (https://doi.org/10.1677/JOE-08-0218)

Waqas MS, Ciccarelli M, Oatley MJ, Kaucher AV, Tibary A \& Oatley JM 2019 Enhanced sperm production in bulls following transient induction of hypothyroidism during prepubertal development. Journal of Animal Science 97 1468-1477. (https://doi.org/10.1093/jas/sky480)

Received 18March2019

First decision 16April2019

Revised manuscript received 3May2019

Accepted 3June2019 